\title{
BMJ Open Gastroenterology
}

\section{Hypoxia induced downregulation of hepcidin is mediated by platelet derived growth factor BB}

\author{
Thomas Sonnweber, ${ }_{1}^{1}$ David Nachbaur, ${ }^{2}$ Andrea Schroll, ${ }^{1}$ Manfred Nairz, ${ }^{1}$ \\ Markus Seifert, ${ }^{1}$ Egon Demetz, ${ }^{1}$ David Haschka, ${ }^{1}$ Anna-Maria Mitterstiller, ${ }^{1}$ \\ Axel Kleinsasser, ${ }^{3}$ Martin Burtscher, ${ }^{4}$ Susanne Trübsbach, ${ }^{3}$ Anthony T Murphy, ${ }^{5}$ \\ Victor Wroblewski, ${ }^{5}$ Derrick R Witcher, ${ }^{5}$ Katarzyna Mleczko-Sanecka, ${ }^{6}$ Chiara Vecchi, ${ }^{7}$ \\ Martina U Muckenthaler, ${ }^{6}$ Antonello Pietrangelo, ${ }^{7}$ Igor Theurl, ${ }^{1}$ Günter Weiss ${ }^{1}$
}

- Additional material is published online only. To view please visit the journal online (http://dx.doi.org/10.1136/

For numbered affiliations see end of article.

Correspondence to Professors Guenter Weiss and Igor Theurl, Department of Internal Medicine VI, Infectious Diseases, Immunology, Rheumatology, Pneumology, Anichstrasse 35, Medical University Innsbruck, Innsbruck A-6020, Austria;

igor.theurl@i-med.ac.at or guenter.weiss@i-med.ac.at

TS, DN, IT and GW contributed equally.

Presented in poster form at the International Bioiron Congress, Vancouver, Canada, May 25-29th, 2011.

Received 22 May 2013 Revised 6 February 2014 Accepted 7 February 2014 Published Online First 5 March 2014 gutjnl-2013-305317).

\section{ABSTRACT}

Objective Hypoxia affects body iron homeostasis; however, the underlying mechanisms are incompletely understood.

Design Using a standardised hypoxia chamber, 23 healthy volunteers were subjected to hypoxic conditions, equivalent to an altitude of $5600 \mathrm{~m}$, for $6 \mathrm{~h}$. Subsequent experiments were performed in $\mathrm{C} 57 \mathrm{BL} / 6$ mice, CREB-H knockout mice, primary hepatocytes and HepG2 cells.

Results Exposure of subjects to hypoxia resulted in a significant decrease of serum levels of the master regulator of iron homeostasis hepcidin and elevated concentrations of platelet derived growth factor (PDGF)$\mathrm{BB}$. Using correlation analysis, we identified PDGF-BB to be associated with hypoxia mediated hepcidin repression in humans. We then exposed mice to hypoxia using a standardised chamber and observed downregulation of hepatic hepcidin mRNA expression that was paralleled by elevated serum PDGF-BB protein concentrations and higher serum iron levels as compared with mice housed under normoxic conditions. PDGF-BB treatment in vitro and in vivo resulted in suppression of both steady state and BMP6 inducible hepcidin expression. Mechanistically, PDGF-BB inhibits hepcidin transcription by downregulating the protein expression of the transcription factors CREB and $\mathrm{CREB}-\mathrm{H}$, and pharmacological blockade or genetic ablation of these pathways abrogated the effects of PDGF-BB toward hepcidin expression.

Conclusions Hypoxia decreases hepatic hepcidin expression by a novel regulatory pathway exerted via PDGF-BB, leading to increased availability of circulating iron that can be used for erythropoiesis.

\section{INTRODUCTION}

\section{SLinked}

- http://dx.doi.org/10.1136/ gutjnl-2014-306970

CrossMark

To cite: Sonnweber T,

Nachbaur D, Schroll A, et al.

Gut 2014;63:1951-1959.
Hypoxic stress commonly occurs as a consequence of environmental or pathological disturbances resulting in reduced oxygen tension in the blood or in tissues. ${ }^{1}$ As compensation, the body tries to expand the oxygen transport capacities as reflected by a rapid increase in circulating erythropoietin (EPO) levels and stimulation of erythropoiesis during hypoxic stress. ${ }^{23}$ A prerequisite for efficient erythropoiesis is a sufficient supply of iron that is needed for the synthesis of haemoglobin. ${ }^{3}$ The higher iron needs for erythropoiesis during hypoxic challenge are met by mobilisation of the metal from body iron stores and increased duodenal iron

\section{Significance of this study}

What is already known on this subject?

- Vertebrates respond to hypoxia with stimulation of erythropoiesis in order to compensate for reduced oxygen tension. To meet the increased need of iron for haemoglobin synthesis under such stress conditions, the central regulator of iron metabolism, hepcidin, is massively suppressed. However, the underlying mechanisms for hepcidin suppression in hypoxia are still elusive.

What are the new findings?

- We demonstrate that platelet derived growth factor (PDGF)-BB is a main inhibitor of hepcidin in hypoxia. Interestingly, PDGF-BB signalling interferes with a recently described signalling mechanism for hepcidin regulation. Notably, we could show that recombinant PDGF-BB directly inhibits hepcidin expression also in wild-type mice.

How might it impact on clinical practice in the foreseeable future?

- Currently, different antihepcidin strategies are evaluated in preclinical and clinical studies for the therapy of anaemia of chronic disease (ACD), which is also found in IBD patients. Therefore, recombinant PDGF-BB could be a valuable new therapy for the treatment of $A C D$.

absorption. ${ }^{5}$ It has been suggested that such adaptations of body iron homeostasis require regulation of the master regulator of iron homeostasis, hepcidin, a mainly liver derived 25-amino acid peptide. $^{7-9}$

Hepcidin controls iron metabolism by binding to the only known cellular iron exporter ferroportin (also known as SCL40A1or Ireg1), thereby inducing its internalisation and degradation. Accordingly, high circulating hepcidin levels-as they are seen in transfusional iron overload or inflammation-block duodenal iron absorption and iron egress from macrophages/monocytes, ${ }^{9} 10$ 